\title{
Is it a Must to be on Campus to Learn? Best Practice of Teaching and Learning Process in Higher Education Through Online Courses During Covid-19 Pandemic
}

\author{
Oikurema Purwati ${ }^{1, *}$ Fahri $^{1}$ \\ ${ }^{1}$ Facultyof Languages and Arts, Universitas Negeri Surabaya, Indonesia \\ *Corresponding author: oikuremapurwati@unesa.ac.id

\begin{abstract}
Covid-19 pandemic brings a lot of changes in all sectors of life, including in educational section. However, it is not changing the vision and mission of educational aims and objectives. This pandemic has changed the mode of teachinglearning process in all level of educational system, from beginners (primary level), secondary level of schooling to higher education. The mode of teaching-learning is switching from real classroom interaction to virtual learning using online platforms, such as WAG, Zoom, Google Meeting, etc. Hence, the use of technology plays significant role in this era. The use of technology here, means technology concerning with interactive platform. It is common that technology can be applied as teaching-learning material and media, such as Edmodo, Blog, Vlog, LMS, etc. Consequently, in the pandemic time right now, it is really needed to apply interactive technological based platforms. As the coming of Covid-19 pandemic is a sudden, the Indonesian Minister of Education decided to use online platform for the process of teaching and learning for all level of education. This kind of practice is also implemented at UNESA. Based on the result of monitoring system as quality assurance, there are 5 platforms applied in the recent times (from March to the end of even semester of 2019/2020 educational year).
\end{abstract}

\section{Keywords: Online Platform, Wag, Zoom, Google Meeting, Vinesa}

\section{INTRODUCTION}

The process of teaching and learning at UNESA has experienced changing from manual (real classroom interaction) to virtual teaching-and learning process [1]. This condition is not expected. It is a sudden for all the educational stakeholders to face this pandemic. Not only lecturers, but also the educational administrative employees and the management officers. The system of teaching and learning process and the management process become Learn from Home (LFH) and Work from Home (WFH). The campus situation has changed tremendously. It seems that there is no activity in campus. Students, lecturers, and all employees are required not to come to campus. This reason to avoid the spread of the virus.

To avoid being infected, the classroom interaction is carried out from home. However, online teaching and learning can be considered as a controversial issue. It is a fact that there are a lot of problems concerning LFH. It is true that it is beneficial for those medium to high class families because they have adequate facilities of internet connection. The parents support their children with the infrastructure facilities. Furthermore, the parents also provide sufficient facilities for their children to learn from home. The parents even accompany their children to do their class assignments given by their teachers. On the contrary, those who belong to the low economic status families, get difficulties in facing LFH. The students must search internet connection and even are not able to buy internet quota. To make it worse, there is only one gadget available in the family while there are more than one child pursuing education in the family. In addition, the internet connection is not available in all part of the country. In urban areas, especially big cities, there is no problem with internet connection. It happens to several students of UNESA that they have to look for internet connection in the rice field. Even, one of the students having thesis examination in the rice field.

Concerning with the issue of LFH, there are several platforms provided to do interaction between teacher and his/her students. They are WAG, google classroom, google meeting, zoom and VINESA (virtual learning UNESA). The choice of mode in teaching-learning process, give teachers choices the appropriate platforms relating to the topic and the number of the students. The availability of the choices of the mode, should motivate teacher/lecturer to improve their competencies in applying technology. This is the teacher duty to determine type of the teaching-learning process. Besides, the teacher 
should consider the condition of the students, whether they live in urban or rural areas, also the economic situation. This is important that participation is not the main concern. It should improve the students' ability to reach the goal It is true that the students will try hard to be able to join the online class whatever their condition. It is not expected, It is not planned, but it is real. As designing lesson, there should be assessment to the students' competences and evaluation to the objective, the process, the material and the media used. LFH should be carried out fulfilling the aspects of course design.

\subsection{Related Work}

\subsubsection{The Result of Monitoring Classroom Interaction Process at Unesa During Covid-19 Pandemic}

According to the result of quality assurance report from UNESA, it is reported that $33 \%$ of lecturers used WAG, then $28 \%$ of all lecturers applied Google Classroom. Then, zoom platform is used by $18 \%$ lecturers in UNESA. While, Google Meet is utilized by $12 \%$ of UNESA lecturers. There are $9 \%$ lecturers use VINESA because it is considered new and not many lecturers know how to use this platform.

Based on the result of classroom observation for monitoring the teaching-learning process at UNESA, it is found that WAG can be considered as the most favorite mode in doing teaching-learning process [2]. This is chosen regarding to the simplicity and low-budget spent by the students. For the lecturers, it is also respected to be flexible mode. Concerning the participation of the students in joining the classroom activities. WAG gives more flexibility in time and money consuming. However, it may give the students more opportunity to communicate with the lecturer because they do not have to wait in expressing their opinion by writing the message. They may join the classroom chat freely to give comment to the lecturer or the other students. It can be understood that more lecturers use WAG platform because they have not prepared for the pandemic and planned the lesson using virtual or technology. Compared to other platforms, such as zoom, or google meeting, WAG is applicable in unusual situation.

Technological platform used during the Covid-19 pandemic

\section{1) WA Group}

WhatsApp Messenger, or simply WhatsApp, is owned by Facebook, Inc. which serves messaging and spoken transmission. It gives opportunity to send text messages and voice messages, make voice and video calls, and share images, documents, user locations, and other media. WhatsApp's can be utilized using mobile devices or desktop computers, also laptop as long as the appliances connected to the Internet.
Before using this service, the users should register to get the service..In educational setting, this service (WA) can be used as a tool for assessing student's work through peer assessment.

\section{2). Google Classroom}

Google Classroom is a free web platform composed by Google that functionss to simplify creating, distributing, and grading assignments. The primary goal of Google Classroom is to streamline the process of sharing files between teachers and students. Google Classroom integrates docs, sheets, slides, gmail, and calendar into a cohesive platform to provide student and teacher communication. Students can be invited to join a class through a private code, or automatically imported from a school domain. Teachers can create, distribute and mark assignments all within the Google ecosystem. Each class creates a separate folder in the respective user's Drive, where the student can submit work to be assessed by a teacher. Assignments and due dates are added to Google calendar, each assignment can belong to a category (or topic). Teachers can evaluate the progress for each student by reviewing revision history of a document, and after being graded, teachers can return work along with comments [3].

\section{3). Google Meet}

In March 2020, Google began offering Meet's advanced features that previously required an enterprise account to anyone using G Suite for Education. During the pandemic, this service is widely used for it does not consume a lot of internet . This service is also free. Free Meet calls can only have a single host and up to 100 participants. Unlike business calls with Meet, consumer calls are not recorded and stored and the company states that consumer data from Meet will not be used for advertisement targeting. While call data is reportedly not being used for advertising purposes, based on an analysis of Meet's privacy policy, Google reserves the right to collect data on call duration, who is participating, and participants' IP addresses. Users need a Google account to initiate calls and anyone with a Google account is able to start a Meet call from within Gmail. Free meet calls have no time limit, but will be limited to 60 minutes starting in September 2020. For security reasons, hosts can deny entry and remove users during a call. Google Meet uses proprietary protocols for video, audio and data transcoding. In short, Google Meet provides opportunity for teacher and students to meet and conduct interaction to replace real classroom communication. 


\section{4). Zoom}

Zoom is one of the solutions to hold classroom meeting during the Covid-19 pandemic.. In addition to hosting virtual meetings, Zoom allows you to host product trainings, video webinars, and more. While in the meeting, you can use Zoom's chat feature to share messages and files with other people on the call. Nowadays, Zoom is widely used for classroom activities and also for webinar seminars or conferences.

\section{5). Vinesa}

It is a platform developed by UNESA. It is recommended for UNESA lecturers to use this platform. It is designed to fulfill the requirement of elearning in which it should be well planned and well developed including the teaching material to the assessment system.

\section{METHODS}

This study analysed the data from quality assurance report from UNESA about the media preferences in conducting online classess. Moreover, this data analysis technique is descriptive-analytical. The data obtained in the form of documents which provide information about the media used by lecturers in conducting online learning and also the observation in teaching learning process, those data were analyzed descriptively.

\section{RESULTS AND DISCUSSION}

Based on personal experience, WA Group seems to be the most useful because many people are familiar in using it. Another reason that WA Group is chosen because it does not spend a lot of money and does not need big internet facility. It can be accessed in many places and in any situation. Accordingly, many lectures at UNESA prefer to use WA group.

The use of WA Group is chosen because it provides flexibility in using it. Furthermore, the use of technological platform during the process of teaching and learning is not planned. It is suddenly changed the process of lecturing. Therefore, more lecturers in UNESA use this platform. In using this platform, the first step is the students are assigned to read the material, and then prepare a presentation based on the chosen topic. After preparing the power point presentation, the student should video his/her own presentation. After that, the student should share the power point presentation and the video in group. The following activity is the other students give comment(s) to develop discussion about a certain topic through writing chat in the group. This activity arises students' motivation and understanding because they have opportunity to prepare their opinion through power point presentation and the video. As all the students are not limited in using their time to give comment in the group, they can give opinion and comment others critically. If there is misconception in the discussion, the lecturer and the students can arrange a virtual meeting through Zoom, Google Classroom and Google Meet. The lecturer and the students determine a certain time approved to have a virtual meeting to give correct understanding to a certain topic of a course. The easy way to use WA Group becomes people' choice for comfort and flexibility.

As the Covid-19 pandemic comes at a sudden, educational activities are not prepared to face this pandemic. Lecturers and teachers who use the technological platform as a material or media, now they have to use them to teach and give lecture. Since the use of communication technology is not planned in designing a lesson, this situation brings a lot of problems because not many places have sufficient internet facility. For the social context, there are a lot of people cannot afford to use this kind of communication due to the economic situation to have a gadget and to access the process of teaching and learning or lecturing. Another reasons, there are still many lecturers and teachers who are not familiar to the communication technology platform. At the same time, many lecturers are not ready to develop e-learning for all subjects

\section{CONCLUSION}

It is necessary to have a well-planned design in lecturing or teaching-learning. This design should be provided with all kinds of material and assessment instrument. In developing, the whole semester lesson plan, it is recommended to propose the use of technology in all of the meetings. This may lead to the effectiveness of the lecturing process. The e-learning model should be the choice for nowadays educational system.

In applying e-learning, it is recommended that the institution should have sufficient band-whit to cover the process of teaching-learning for all courses. To prepare e-learning, there is a need to train not only the lecturers but also the technicians to be help desk. The preparation to conduct e-learning involves students' participation as well. The students are required to read the materials provided before joining the online course. In short, the success of conducting online course depends on all units in a higher institution.

\section{REFERENCES}

[1] L. Mishra, et al., "Online Teaching Learning in Higher Education during Lockdown Period of COVID-19 Pandemic", International Journal of 
Educational Research Open. 2020. [Online],

Available:

Sciencedirect.com/science/article/pii/S266637402 0300121.

https://doi.org/10.1016/j.ijedro2020.100012

[2] I. F. Rahmadi, "WhatsApp Group for Teaching \& Learning in Indonesian Higher Education: What's UP?", International Journal of Interactive Mobile Technologies (IJIM), vol. 14, no. 13, pp. 150, 2020. https://doi.org/10.3991/Ijim.v14i13.14121

[3] A. Flynn and B. Lutz, "Google Classroom”. 2014. Online Tools for Teaching \& Learning. [Online], Available:

https://blogs.umass.edu/onlinetools/communitycentered-tools/google-classroom/

[4] K. Fink, Kimmie, “Zoom 101 for Teachers”, 2020. [Online], Available:

https://www.weareteachers.com/zoom-forteachers/. 